\title{
Assessment of the Awareness, Attitude and Environmental Literacy about Environmental Issues and Challenges (Case study: Yazd Citizen's View in 2017)
}

hamideh mihanpour ${ }^{1}$, maryam khashij ${ }^{2}$, zahra shamsizadeh ${ }^{2}$, maryam Gholami ${ }^{2}$, Aliasghar Ebrahimi $^{2 *}$, Hassan rezaeipandari ${ }^{2}$, Roya malekahmadi ${ }^{2}$, ala $\operatorname{arsham}^{2}$, fatemeh $\operatorname{parizan}^{2}$, vahid jafari $^{3}$

${ }^{1}$ MSc of occupational health engineering, instructor, faculty of paramedicine abarkouh, Genetic and Environmental Adventures Research Center shahid sadoughi university of medical sciences, yazd, iran.

2 Environmental Science and Technology Research Center, Department of Environmental Health Engineering, Shahid Sadoughi University of Medical Sciences, Yazd, Iran.

${ }^{3}$ Department of Environmental Engeeniering, Faculty of Natural Resources and the Environment, Science \& Research Branch, Islamic Azad University, Tehran, Iran.

* corresponding author: Email: ebrahimi20007@gmail.com Tel:+989132679641

\section{Introduction}

Environmental education is the process of educating individuals on environmentally relevant issues to achieve solutions to solve these issues, obtain the required knowledge and skills to acquire a positive attitude towards the environment and increase motivation in solving environmental issues [1]. The concept of environmental literacy was first introduced in 1968 by Charles as the level of individuals' knowledge and awareness in relation to the environment [2]. Essentially, environmental literacy is the understanding of interactions between natural systems and human-social systems [3]. In recent years, this subject has been identified as one of the most prominent sections of environmental education. Four main areas of environmental literacy include environmental knowledge, environmental attitudes, environmental behavior perception and environmental concerns [4]. The emergence of environmental issues is associated with human occupation of the environment. In the past century, factors such as rapid population growth, urbanization and industrialization of communities has had detrimental effects on the environment [5]. Currently, humans face a set of environmental issues as global warming, ozone layer destruction and species extinction that affect the sustainability of life. The most vital way of dealing with environmental threats is to educate people [4]. The environment provides the necessary materials and energy to meet basic human community needs, and all human activities depend on a sound and sustainable environment. In general, at least one activity performed by every human being has positive and negative effects on the environment. Environmental pollution and degradation is now evident as one the negative consequences of human activities. Also, the effect of these consequences on the economy and livelihood of the community should 
not be neglected. Although today, many people consider themselves as environment advocates, but by virtue of their positive attitudes, do not behave positively in preserving the environment. Essentially, humans are both the victims and cause of environmental degradation, such that this era is deemed the era of environmental crisis. Environmental illiteracy is what exacerbates this crisis [6]. Today, environmental organizations and institutions are responsible for protecting the environment and maintaining sustainable productivity. Protecting the environment reduces environmental costs incurred by these organizations. Consequently, environmental literacy has become a vital issue among university researchers. In general, it is argued that the level of knowledge and perception of each individual on environmental issues is related to the desire to participate in environmentally related programs and is necessary for environmental protection. Although there is a need to change the attitude towards the environment, the education available in this field is insufficient [7]. People only take measures in preventing the destruction of these resources once they become aware of the value of natural resources and the environment [3]. The most important objective of environmental education is to promote environmental literacy and thus may lead to an improved quality of the environment and the development of a sustainable environment [7]. Environmental education will aid individuals to raise awareness, perception and improve attitude between human activities and the environment [3]. According to Lillah, lack of knowledge and awareness of environmental issues has restricted any type of individual or organizational measures in relation to the environment [8]. Therefore, considering the importance of the environment and its vital role in sustainable development and considering that the knowledge and attitude of the people of Yazd has not yet been assessed in this field, thus this research aims to assess the level of awareness and attitude of "environmental literacy" of the people of Yazd in relation to environmental issues and challenges in the year 2017.

\section{Research methods}

In this descriptive-analytical study, the level of environmental literacy (knowledge and attitude) of the people of Yazd regarding environmental challenges and issues has been measured and assessed. The sample size was derived based on the Cochran formula on 410 people from residents over the age of 18 in the city of Yazd. Sampling was done by the systematic random sampling method. Therefore, the urban areas of Yazd were divided into 3 clusters and from each cluster a sample was randomly selected in proportion to its population.

The data collection tool was a researcher made questionnaire consisting of two sections: 1- a demographic questionnaire, 2- a questionnaire related to the environmental literacy (awareness, attitude and practices) of the research subjects. The questions of the questionnaire were verified by 10 qualified individuals of the board members and its reliability was confirmed by a Cronbach's alpha coefficient of 0.93 . The awareness questionnaire consisted of 10 questions to assess the awareness level of issues related to water, air, waste, sewage, green areas and parks, urban industries and industrialization, energy and fuel consumption in homes, industrial development and relevant pollution, city cleaning and city cleanliness. For each question, the correct answer was scored as one and the incorrect answer was scored as zero. The total score 
scale of this questionnaire was from 0 to 10 and this interval was divided into three parts of weak awareness, moderate awareness and high awareness. Higher marks showed higher awareness. The attitude questionnaire consisted of 15 questions that were scored using the five level Likert scale (totally agree-agree-undecided-disagree-totally disagree) such that the maximum score was 75 and the minimum was 15 . The attitude level categorization was obtained based on the average of individual's total score (in two groups of less than average and equal to/greater than average). The practices questionnaire was also created by a researcher tool and consisted of 24 questions that were each scored using the 4 level Likert scale (always, usually, sometimes, never) such that the maximum score was 96 and the minimum score was 24 whereas the higher score showed more favorable practices.

The collected data was analyzed by the SPSS-22 software using descriptive statistics along with Mann-Whitney, Kruskal-Wallis and Chi-Square tests in addition to the Pearson correlation coefficient. In this study, the confidence interval was $95 \%$ and the significance level was 0.05 .

\section{Results}

In this study, 404 questionnaires were completed and assessed. Based on the obtained results $55.4 \%$ (224 individuals) were male, $44.6 \%$ were female and $53.5 \%$ were married. In terms of age, the majority of individuals (40.1\%) were in the 18-27 age group. Also, in terms of education level, most participants had at least a bachelor's degree (31.2\%). Students had a higher share of the employment status frequency distribution (33.4\%). In terms area of residence, $64.1 \%$ resided in region $2.51 .3 \%$ of the participants believed that the main environmental issue in Yazd was water deficiency and pollution. $28.8 \%$ of individuals stated that the country's main electricity source is fossil fuels. Most of the participants (73.3\%) considered colors, solvents and batteries as hazardous waste and only $30.4 \%$ believed that brick and industrial furnaces were the cause of Yazd's air pollution. 79\% of the participants believed that recent droughts had an impact on air pollution. Also, $61.4 \%$ considered $\mathrm{CNG}$ as a less polluting fuel. Only $46.9 \%$ of individuals believed that waste is buried upon collection. $47.3 \%$ of individuals considered uncontrolled use of agricultural fertilizers, industrial activity and communities' sewage as the reasons for soil contamination. $60.3 \%$ of participants stated that unsanitary dumping of waste was the main cause of soil and water pollution. $36.8 \%$ of participants believed that the three factors of population, excessive water resources usage and drought were the main reasons for the reduction of available water resources.

Based on the results of Table 1 which presents the relationship between the knowledge, attitude and practices of research subjects in terms of demographic variables, there is statistically significant relationship between the awareness score and the age, education level and employment status variables. The relationship between the practices score and the age, marital status and area of residence variables is statistically significant. 
Table 1: Mean \pm SD scores of individual's knowledge, attitude and practices.

\begin{tabular}{|c|c|c|c|c|c|c|c|}
\hline \multicolumn{2}{|c|}{ Category } & \multicolumn{2}{|c|}{ knowledge } & \multicolumn{2}{|c|}{ attitude } & \multicolumn{2}{|c|}{ practices } \\
\hline & & Mean & SD & Mean & SD & Mean & SD \\
\hline \multirow[t]{3}{*}{ Gender } & Male & 5.06 & 2.14 & 67.07 & 7.03 & 66.86 & 7.7 \\
\hline & Female & 4.74 & 2.19 & 65.87 & 7.12 & 66.75 & 8.1 \\
\hline & ${ }^{*} P$ value & \multicolumn{2}{|c|}{0.274} & \multicolumn{2}{|c|}{0.106} & \multicolumn{2}{|c|}{0.739} \\
\hline \multirow{3}{*}{$\begin{array}{c}\text { Marital } \\
\text { status }\end{array}$} & Single & 4.98 & 2.17 & 67.1 & 7.41 & 67.61 & 7.74 \\
\hline & Married & 4.85 & 2.17 & 65.88 & 7.98 & 65.89 & 7.95 \\
\hline & ${ }^{*}$ P value & \multicolumn{2}{|c|}{0.037} & \multicolumn{2}{|c|}{0.356} & \multicolumn{2}{|c|}{0.000} \\
\hline \multirow[t]{6}{*}{ Age } & $18-27$ & 4.93 & 2.13 & 65.53 & 7.54 & 65.36 & 8.23 \\
\hline & $28-37$ & 5.23 & 2.09 & 66.71 & 7.27 & 69.4 & 6.37 \\
\hline & $38-47$ & 4.99 & 2.42 & 66.99 & 8.62 & 65.27 & 7.95 \\
\hline & $48-57$ & 4.24 & 1.92 & 68.18 & 6.69 & 68.42 & 8.13 \\
\hline & $58-68$ & 4.24 & 1.74 & 68.24 & 7.58 & 70.36 & 5.94 \\
\hline & ${ }^{\text {*P }}$ value & \multicolumn{2}{|c|}{0.037} & \multicolumn{2}{|c|}{0.356} & \multicolumn{2}{|c|}{0.000} \\
\hline \multirow[t]{6}{*}{ Education } & illiterate & 3.25 & 1.76 & 64 & 5.94 & 69.33 & 5.43 \\
\hline & $\begin{array}{c}\text { Under } \\
\text { diploma }\end{array}$ & 4.77 & 1.97 & 66.75 & 6.79 & 66.96 & 6.18 \\
\hline & $\begin{array}{l}\text { Associate } \\
\text { Degree }\end{array}$ & 4.6 & 2.02 & 66.62 & 8.47 & 65.83 & 7.92 \\
\hline & Bachelor & 4.99 & 2.14 & 67.38 & 8.12 & 67.26 & 8.44 \\
\hline & $\begin{array}{c}\text { Master's and } \\
\text { Ph.D }\end{array}$ & 5.4 & 2.32 & 65.98 & 7.08 & 67.12 & 8.19 \\
\hline & "P value & \multicolumn{2}{|c|}{0.004} & \multicolumn{2}{|c|}{0.626} & \multicolumn{2}{|c|}{0.449} \\
\hline \multirow[t]{6}{*}{ Job } & Employee & 4.71 & 2.14 & 66.36 & 8.36 & 67.04 & 8.63 \\
\hline & Academic & 4.77 & 2.28 & 65.42 & 7.59 & 66.04 & 7.83 \\
\hline & Student & 4 & 2.09 & 61.81 & 5.09 & 67.31 & 8.17 \\
\hline & housewife & 4.71 & 1.89 & 67.87 & 6.81 & 66.71 & 4.48 \\
\hline & $\begin{array}{c}\text { Self- } \\
\text { employed }\end{array}$ & 4.45 & 2.07 & 68.18 & 7.39 & 67.46 & 8.12 \\
\hline & ${ }^{*} \mathbf{P}$ value & \multicolumn{2}{|c|}{0.033} & \multicolumn{2}{|c|}{0.004} & \multicolumn{2}{|c|}{0.677} \\
\hline \multirow[t]{4}{*}{ Residence } & 1 & 5.21 & 2.02 & 66.56 & 7.37 & 66.52 & 7.29 \\
\hline & 2 & 4.73 & 2.12 & 66.76 & 7.57 & 66.57 & 7.72 \\
\hline & 3 & 5.36 & 2.83 & 64.64 & 9.57 & 69.7 & 10.28 \\
\hline & ${ }^{*}$ P value & \multicolumn{2}{|c|}{0.12} & \multicolumn{2}{|c|}{0.438} & \multicolumn{2}{|c|}{0.031} \\
\hline
\end{tabular}

${ }^{*}$ Mann-Whitney

${ }^{* *}$ Kruskal Wallis Test 
Table 2 presents descriptive analysis of awareness, attitude and practices scores. The mean and standard deviation of these scores were $4.92 \pm 2.17,66.53 \pm 7.7$ and $66.81 \pm 7.78$ respectively. Results indicate that the attitude score of the majority of participants $(51.5 \%)$ was lower than average, but the awareness and knowledge score was mostly average (Table 3).

Table 2. Mean \pm SD of knowledge, attitude and practice scores

\begin{tabular}{cccccccc}
\hline Variable & Mean & SD & Min & Max & $\begin{array}{c}\text { 25th } \\
\text { percentile }\end{array}$ & $\begin{array}{c}\text { 50th } \\
\text { percentile }\end{array}$ & $\begin{array}{c}\text { 75th } \\
\text { percentile }\end{array}$ \\
\hline knowledge & 4.92 & 2.17 & 0 & 10 & 3 & 5 & 6 \\
attitude & 66.53 & 7.7 & 43 & 90 & 61 & 66 & 72 \\
practice & 66.81 & 7.87 & 43 & 91 & 61 & 66 & 72 \\
\hline
\end{tabular}

Table 3. Frequency of Levels of Knowledge and Attitude Scores

\begin{tabular}{|c|c|c|c|}
\hline & Variable & Number & \% \\
\hline \multirow{2}{*}{ Attitude } & $<$ Mean & 208 & 51.5 \\
\cline { 2 - 4 } & $>$ Mean & 196 & 48.5 \\
\hline \multirow{2}{*}{ Knowledge } & Weak & 162 & 40.1 \\
\cline { 2 - 4 } & medium & 191 & 47.3 \\
\cline { 2 - 4 } & Good & 51 & 12.6 \\
\hline Total & & 404 & 100 \\
\hline
\end{tabular}

There is significant relationship between age, income level and awareness levels but no significant relationship with attitude levels. There is no significant relationship between gender, education level, marital status, area of residence, awareness level and attitude ( $p$-value $>0.05$ ). Based on Table 4, there is a significant relationship between awareness levels and occupation whereas this relationship was not approved in regard to awareness level.

Table 4. Job Relationship with Attitude Levels

\begin{tabular}{|c|c|c|c|c|c|}
\hline \multirow{2}{*}{ Job } & Attitude & $<$ Mean & $>$ Mean & Total & p-value* \\
\cline { 1 - 5 } Employee & $\mathrm{N}$ & 52 & 46 & 98 & \\
\cline { 2 - 5 } & $\%$ & 53.1 & 46.9 & 100 & \multirow{2}{*}{0.014} \\
\hline \multirow{2}{*}{ Academic } & $\mathrm{N}$ & 79 & 56 & 135 & \\
\cline { 2 - 5 } & $\%$ & 58.5 & 41.5 & 100 & \\
\hline \multirow{2}{*}{ Student } & $\mathrm{N}$ & 12 & 4 & 100 & \\
\cline { 2 - 5 } & $\%$ & 75 & 25 & & \\
\hline
\end{tabular}




\begin{tabular}{|c|c|c|c|c|}
\hline \multirow{2}{*}{ housewife } & $\mathrm{N}$ & 18 & 20 & 38 \\
\cline { 2 - 5 } & $\%$ & 47.4 & 52.6 & 100 \\
\hline \multirow{2}{*}{$\begin{array}{c}\text { Self- } \\
\text { employed }\end{array}$} & $\mathrm{N}$ & 47 & 70 & 117 \\
\cline { 2 - 5 } & $\%$ & 40.2 & 59.8 & 100 \\
\hline \multirow{2}{*}{ Total } & $\mathrm{N}$ & 208 & 196 & 404 \\
\cline { 2 - 5 } & $\%$ & 51.5 & 48.5 & 100 \\
\hline
\end{tabular}

${ }^{*}$ Chi-square

Since the knowledge, attitude and practices scores did not follow the normal distribution, Spearman's statistical test was used to assess the correlation and relations. Table 5 shows that there is a positive and significant correlation between the awareness, attitude and practices scores.

Table 5. Correlation between knowledge, attitude and performance scores

\begin{tabular}{|c|c|c|c|}
\hline Variable & knowledge & attitude & performance \\
\hline knowledge & 1 & & \\
& $0.323^{* *}$ & & \\
\hline attitude & 0.000 & 1 & \\
\cline { 2 - 3 } & $0.292^{* *}$ & $0.28^{* *}$ & 1 \\
\hline performance & 0.000 & 0.000 & \\
&
\end{tabular}

** Significance level of 0.01

Spearman correlation

\section{Discussion and conclusion}

Considering the importance of the environment and its fundamental role in sustainable development, as well as reducing the detrimental effects of human activities on the environment, the acquirement of environmental literacy is regarded as an essential factor. In all behaviors, knowledge is regarded as a tool to surpass psychological barriers such as ignorance and aberration. For this reason, it is vital to measure the people's preceding knowledge [9]. The aim of this study is to assess the awareness and attitude of the people of Yazd's "environmental literacy" in relation to environmental issues and challenges in 2017.

$55.4 \%$ (224 individuals) were male, $44.6 \%$ were female and $53.5 \%$ were married. In terms of age, the majority of individuals (40.1\%) were in the 18-27 age group. Also, in terms of education level, most participants had at least a bachelor's degree (31.2\%). Students had a higher share of the employment status frequency distribution (33.4\%). In terms area of residence, $64.1 \%$ resided in region 2. 
Results showed that the awareness of $47.3 \%$ of participants regarding the environment was average which is approximately similar to the results of the research conducted by Aminrad et al. [10] and Oguz \& Kavas [11] based on the adequate or inadequate nature of the research subjects' environmental awareness. However, these results were inconsistent with results obtained by Hooshmandan Moghadam et al, Salehi and Pazokinejad who reported an upper awareness level. Today, with extensive mass media and communications technologies that are available as well as the existence of several environmental crises which has caused governments to invest significantly in producing television, radio and printed programs in this field, higher awareness levels would seem more likely. Maybe the reason for average awareness is that the subject of energy is a specialized and less general which entails lower levels of awareness in regard to this subject. In assessing the relationship between the use of mass media (with emphasis on television), by enhancing the teachers' environmental literacy by Shobeiri et al (2012), research results showed that statistically, there is a relationship between watching mass media and the knowledge, attitude, practices and in general, the environmental literacy of teachers [12]. The results of the study by Mesdaghinia indicated that over $80 \%$ of people have acquired awareness through television whereas newspapers and social dialogues were next as means of awareness which shows the prominent power of television in informing people about the environmental health issues [13]. Therefore, it seems it is more beneficial to use this medium in progressing health programs namely health education, and to produce appealing environmental documentaries which have an expert explaining relevant issues at the end of the programs. In recent years, due to large reception of virtual networks, it is recommended to create groups or channels on social networks in order to efficiently utilize mobile phones and acquire adequate information that is appropriate to the age and education of users as well so to provide and share necessary information and informative environmental content.

Based on the conducted assessment, $51.3 \%$ of the participants believed that the most prominent environmental issue in Yazd was water deficiency and pollution. 28.8\% of individuals declared that the most important source of electricity for the country is fossil fuels. The results of the research conducted by Shobeiri et al. (2015) on teaching energy literacy to operationalize environmental behavior showed that there is a significant relationship between energy literacy, energy saving and environmental protection. Also, teaching energy literacy had a direct relationship with the mentioned factors and by increasing the level of energy literacy among students, the level of energy savings, environmental behavior and environmental protection will also be enhanced [12, 14]. By referring to the study conducted by Karimzadegan, Meybodi and Erdogan et al. on the analysis of academic education goals with the approach of environmental literacy components in Iran and Turkey, it seems the most favorable way to provide environmental awareness during childhood is through the production of a new and independent syllabus in this field [3, 15]. Social education textbooks should take into account students' emotional tendencies towards the environment and cognitive skills that they utilize to deal with environmental issues. Also, a study conducted by Kadir Karatekin in 2012 titled "Environmental 
Literacy" regarding social textbooks in Turkish primary schools showed that social textbooks were not sufficient in terms of environmental literacy components [5].

The practices score was also average which was expected because with this inappropriate level of awareness, environmental protection should not be expected from individuals. Although it should be considered that even with high levels of environmental literacy, people often exhibit behavior that is not environmentally friendly because they may think that their behavior will not impact the environment [9].

In a study conducted by Owusu on the environmental literacy of employed students in Ghana, 2017, results showed that environmental literacy among these students was relatively inadequate and in all cases, most respondents were familiar with the $\mathrm{CSR}^{1}$ term resulting in a higher average score whilst water use, waste management, global warming, renewable and non-renewable natural sources were recorded above the overall average score [16].

The attitude score of most people in this study was lower than average which is inconsistent with the result of the study conducted by Denis Saribas et al. in 2014 on the relationship between environmental literacy and self-efficacy beliefs towards environmental education. They reported relatively high levels of attitudes, concerns and environmental issues perception even though participants did not possess environmental literacy or sufficient self-efficacy in relation to the environment [4].

In the present study, there was no significant relationship between gender, education level, marital status, area of residence, awareness level and attitude levels. Salehi Omran et al. (2007) assessed primary school teachers' environmental knowledge, attitude and skills in Mazandaran province with results showing positive attitude of female environmental teachers compared to male teachers. Furthermore, male teacher's environmental literacy was higher compared to female teachers [17]. Arbaat Hassan et al. (2011) also reported that there is a significant relationship between genders in terms of knowledge, awareness, and practices in relation to the environment. However, there was a significant difference in attitude among female students compared to male students [18]. A free study conducted by Shirazi et al. in the city of Yasuj showed that women's awareness concerning healthy drinking water, waste disposal, and air hygiene is higher compared to males. This was also true in married couples compared to singles. Evans et al. conducted a study in New York which showed that the awareness of Manhattan women was high in regard to environmental risks [19].

The awareness score was statistically significant in relation to the age, education level and employment status variables. In this study it was observed that students in the science field had higher awareness compared to students of other fields but there was no significant relationship in students of other fields in terms of attitude and practices [18].

In this study, occupation was an effective factor in awareness levels even though it did not affect attitude levels. The results of the assessment on pre-employed teachers' environmental literacy in Turkey, as a barometer for the development of teacher training programs by Gaye Tuncer et al. (2009) showed that efforts to revitalize the education curriculum in Turkey were promising. In

\footnotetext{
${ }^{1}$ Corporate Social Responsibility
} 
addition, teachers' environmental background prior to employment was positively related to their environmental literacy and attitude [20]. The opportunities and facilities offered and the sense of efficiency may play an effective role in promoting environmental literacy [21].

Based on the results of this study, awareness, attitude and practices of participants concerning some of the environmental issues and institutions that operate in the field of environmental pollution control in the country appears to be inadequate. Considering that environmental risks are increasing at local and global scales and in this country, especially in large cities, environmental pollution namely air pollution is continuously increasing due to various reasons such as population growth, increasing number of cars, non-standard cars in terms of environmental criterion etc. considering the importance of the role of environmental factors regarding communities' health due to the expansion of automated life specifically in the country's major cities, it is necessary to conduct various researches to identify and control these factors. The conduction of interventional studies to identify appropriate solutions and to operationalize such solutions is of extremely high priority in this regard.

Cultural beliefs provide a broad and profound stage to improve the management of environmental issues. Therefore, understanding and identifying the practices of various cultures may be extremely vital in taking the first step in promoting resource management among various cultural groups to prevent conflicts and to resolve environmental issues [22]. The implementation of educational and informative programs based on the cultural foundations of various communities in different regions of the country may be effective in improving the awareness of people regarding the environmental pollution control institutions field and their cooperation with these institutions for the efficient management of environmental pollution control. Considering the people's reception of health plans such as plans to eradicate viral contagious diseases, the education of citizens to improve their awareness of environmental pollution and resulting diseases may entail increased cooperation in this field. Also, producing participatory and encouraging programs for families and citizens may be useful and worthwhile. Inter-organizational cooperation within organizations active in the environmental pollution control field and the allocation of sufficient financial resources in this regard may aid in further advancing the objectives of these organizations.

Among respondents, $61.4 \%$ reported $\mathrm{CNG}$ as a less polluting factor. Based on a study conducted in Denmark, results showed that automobile fumes and wood scraps are the most prominent sources of airborne particles whilst the main reason of human exposure to these particles in open environments is their high density especially in urban areas that are also more densely populated $[13,23]$.

One of the limitations of this study was the collection of data through a questionnaire which assumes that respondent's answers are honestly and accurately; although some respondents may not be honest in answering the questions. Information was collected using a self-report questionnaire, some of which may not have been answered accurately by participants.

References 
1. UNESCO P. Final Report, Intergovernmental conference on environmental education, Tbilissi (USRR), 14-16 oct., 1977. Paris (France); 1978.

2. Ertekin T, Yüksel Ç. The Role of Ecological Literacy Education with Academic Support in Raising Environmental Awareness for High School Students:“Enka Ecological Literacy Summer Camp Project Case Study". Procedia-Social and Behavioral Sciences. 2014;120:124-32.

3. Karimzadegan H, Meiboudia H. Exploration of environmental literacy in science education curriculum in primary schools in Iran. Procedia-Social and Behavioral Sciences. 2012;46:404-9.

4. Saribas D, Teksoz G, Ertepinar H. The relationship between environmental literacy and self-efficacy beliefs toward environmental education. Procedia-Social and Behavioral Sciences. 2014;116:3664-8.

5. Karatekin K. Environmental literacy in Turkey primary schools social studies textbooks. ProcediaSocial and Behavioral Sciences. 2012;46:3519-23.

6. Safdari M, Ehrampoush M, Ghaneian M, Morowati M, Mohammadloo A, Mirzaei Alavijeh M. Knowledge, attitude and practice among Yazd Housewives regarding to recycling solid Waste. Journal of Toloo-e-Behdasht. 2012;40(3):22-32.

7. Owusu GMY, Ossei Kwakye T, Welbeck EE, Ofori CG. ENVIRONMENTAL LITERACY OF BUSINESS STUDENTS IN GHANA. International Journal of Sustainability in Higher Education. 2017;18(3).

8. Lillah R. Environmental literacy: A Needs Analysis: Nelson Mandela Metropolitan University; 2011.

9. Salehi S, Karimzade S. A Study on Relationship between Environmental Knowledge And Environmental Behavior. Journal of cutural studies and communications. 2011;24:159-73.

10. Aminrad Z, Zakariya S, Hadi AS, Sakari M. Relationship between awareness, knowledge and attitudes towards environmental education among secondary school students in Malaysia. World Applied Sciences Journal. 2013;22(9):1326-33.

11. Oğuz D, Kavas S. Environmental awareness of university students in Ankara, Turkey. African Journal of Agricultural Research. 2010;5(19):2629-36.

12. Shobeiri S.M, Farajollahi M, Koohi Aghdam E, Meiboudi Meiboudi H. The Relationship between Using Mass Media (with Emphasis on TV) and Promotion of Teachers' Environmental Literacy. Information and Communication Technology in Educational Sciences. 2013;4(1):23-40.

13. Mesdaghinia a, Yunesian m, Naseri s, Jafari a, Moradi a, Farahdoust f, et al. The knowledge of Tehran citizens on environmental pollutions, related health effects and their information sources. scientific magazine yafte. 2007;9(1):3-13.

14. Craig CA, Allen MW. The impact of curriculum-based learning on environmental literacy and energy consumption with implications for policy. Utilities Policy. 2015;35:41-9.

15. Erdoğan M, Kostova Z, Marcinkowski T. Components of Environmental Literacy in Elementary Science Education Curriculum in Bulgaria and Turkey. Eurasia Journal of Mathematics, Science \& Technology Education. 2009;5(1). 
16. Owusu GMY, Ossei Kwakye T, Welbeck EE, Ofori CG. Environmental literacy of business students in Ghana. International Journal of Sustainability in Higher Education. 2017;18(3):415-35.

17. Salehi omran E, Aghamohammadi A. Evaluating of Knowledge, attitudes and environmental skills of primary school teachers in Mazandaran province. Journal of Education. quartery journal of education. 2008;24(3):91-117.

18. Hassan A, Rahman NA, Abdullah SISS. The level of environmental knowledge, awareness, attitudes and practices among UKM students. 2011.

19. Evans DT, Fullilove MT, Green L, Levison M. Awareness of environmental risks and protective actions among minority women in Northern Manhattan. Environmental Health Perspectives. 2002;110(Suppl 2):271.

20. Tuncer G, Tekkaya C, Sungur S, Cakiroglu J, Ertepinar H, Kaplowitz M. Assessing pre-service teachers' environmental literacy in Turkey as a mean to develop teacher education programs. International Journal of Educational Development. 2009;29(4):426-36.

21 .Hemmati Z, Shobeiri SM. Environmental Culture and the Factors Affecting It (Case Study: the Citizens of Shiraz). Iranian Journal of Cultural Research 2016;8(4):19.

215-7

22. Flanagan C, Laituri M. Local cultural knowledge and water resource management: The Wind River Indian Reservation. Environmental Management. 2004;33(2):262-70.

23. Palmgren F. Air pollution: Review of Danish knowledge on particulate matter (PM).Danish Environment Newsletter. 2003;28. 